\title{
Improving the fermentability of pre-hydrolysis liquor to produce ethanol and xylonic acid by removing fermentation inhibitors using polystyrene divinylbenzene resin
}

\author{
Caoxing Huang \\ Nanjing Forestry University \\ Wenqian Lin \\ Nanjing Forestry University \\ Yuxuan Shi \\ Nanjing Forestry University \\ Yayue Zheng \\ Nanjing Forestry University \\ Qiang Yong ( $\square$ swhx@njfu.com.cn ) \\ Nanjing Forestry University
}

\section{Research}

Keywords: pre-hydrolysis liquor, polystyrene divinylbenzene, inhibitors, fermentability, bioconversion

Posted Date: September 2nd, 2020

DOI: https://doi.org/10.21203/rs.3.rs-70189/v1

License: (c) (i) This work is licensed under a Creative Commons Attribution 4.0 International License. Read Full License

Version of Record: A version of this preprint was published on November 12th, 2020. See the published version at https://doi.org/10.1186/s13068-020-01828-3. 


\section{Abstract \\ Background}

The existences of soluble lignin, furfural and HMF in industrial pre-hydrolysis liquor (PHL) can inhibit its bioconversion into bioethanol and other bio-chemicals. Although various technologies have been carried out to remove these inhibitors, a undesirable sugars removal is also happened during the process. Hence, polystyrene divinylbenzene (PS-DVB) resin was used as adsorptive material to simultaneously remove fermentation inhibitors while retain sugars with higher yield for improving the fermentability of PHL after acid-hydrolysis (A-PHL) treatment. The fermentability of treated PHL was evaluated by the bioconversion into ethanol and xylosic acid (XA).

\section{Results}

Results showed that an highest xylose concentration $(101.1 \mathrm{~g} / \mathrm{L})$ in PHL could be obtained by acidhydrolysis at $100^{\circ} \mathrm{C}$ for $80 \mathrm{~min}$ with $4 \%$ acid, while concentration of fermentation inhibitors (furfural, HMF and lignin) could also be significantly improved. After treating, not only $97 \%$ of lignin, $92 \%$ of furfural, and $97 \%$ of HMF were removed from solution, but also $96 \%$ of xylose was retained for subsequent fermentation. With resin treatment, the fermentability of A-PHL could be improved by $162-$ $282 \%$ for ethanol production from A-PHL with $30-50 \mathrm{~g} / \mathrm{L}$ xylose and by $18-828 \%$ for XA production from A-PHL with $90-150 \mathrm{~g} / \mathrm{L}$ xylose.

\section{Conclusions}

These results confirmed that PS-DVB resin can remove inhibitors from PHL before producing value-added products by bioconversion. In addition, the work will ideally provide a concept by which pulping facilities could go about producing value-added chemicals from existing waste streams.

\section{Background}

Pre-hydrolysis is a necessary first step in kraft-based dissolving pulp production at pulp and/or paper mills [1, 2]. Steam or hot water are used as the media to treat wood chips during the pre-hydrolysis process, which acts to hydrolyze the majority of hemicellulose and a portion of lignin from cell wall into a prehydrolysis liquor $(\mathrm{PHL})$ stream. Carbohydrates, furfurals and lignin fragments in PHL exist in the forms of solutes, particulates, and colloids, there PHL is typically regarded as a waste stream [3-5]. Strategies for managing this aqueous stream water usually involves mixing it back in with the black liquor prior to introduction into the operation's recovery boiler. However, the dissolved hemicellulose in $\mathrm{PHL}$ only possesses the heat value of $7400 \mathrm{BTU} / \mathrm{b}$, which is significant lower than that of the lignins that dominate black liquor (11,300 BTU/b for softwood, 10,600 BTU/b for hardwood) [6, 7]. This means that the current strategy for disposing of PHL is actually reducing the energy efficiency of the kraft pulping 
operation. Because the produced PHL contains various amounts of monomeric and oligomeric sugars, as well as soluble lignin, it is possible to envision utility of this waste stream to generate high value. This strategy is in line with the overall biorefinery concept, where multiple value-added products are generated by a process which consumes lignocellulosic material [8-10].

Xylose is an important industrial commodity chemical that can be used to produce xylitol, a valuable chemical to both the pharmaceutical and food industries [11]. In the bio-refinery concept, xylose can be sustainably used to produce bio-ethanol by fermentation, which is currently obtained from the starchbased crops. Developing the bio-ethanol has been regarded as one of the approaches towards reducing $\mathrm{CO}_{2}$ emissions from fossil fuel consumption [12]. Recently, xylonic acid (XA), one of the top 30 high-value chemicals in NREL and PNNL report, can also be produced from xylose by chemical, electrochemical, or fermentative methods $[13,14]$. In acknowledgment of the potentially disruptive usages of a lignocellulose-derived supply of xylose or its derivatives, various types of biomass have been explored at different levels of scale for producing xylose via an acid hydrolysis process [15-16]. As can be expected, the technologies around acid hydrolysis processes require carefully orchestrated plans for funding and maintaining construction, operation, and management [17]. Considering the current industrial presence of xylose in PHL, efforts should also be carried out to upgrade the stream (as opposed to burning it) into value-added sustainable chemicals. Doing such approach will open an opportunity for producing biochemicals from waste water in most existing pulp mills conducting pre-hydrolysis processes.

During prehydrolysis a small portion of lignin can be depolymerized into water soluble oligomers. Jiang et al. (2020) [18] found that the extensive lignin degradation occurs during prehydrolysis by homolytic cleavage of the aryl-ether bonds, resulting in the PHL contain with abundant of aromatic compounds of vanillin and syringaldehyde. In addition, furfural and hydroxymethylfurfural (HMF) also exist in PHL due to monosaccharide dehydration during prehydrolysis [19-21]. Each of these aforementioned monosaccharide byproducts are fermentation inhibitors for microbial production of bioethanol, $\mathrm{XA}$, and other bio-chemicals [22-23]. Therefore, to efficiently utilize the xylose present in PHL, these inhibitors should be removed from PHL to improve fermentability and xylose consumption efficiency.

Various methods have been explored for removing inhibitors from PHL. For example, acidification has been tried to treat the PHL, however only $3.8 \%$ of the soluble lignin was rendered as a filterable precipitate [24]. Wang et al., (2015) [25] used membrane filtration with different molecular mass cut-offs on PHL and found that the method had limited ability in purifying due to overlaps between molecular weight distributions in the carbohydrate fractions. A different approach involved adding polydiallyldimethylammonium chloride ( $\mathrm{p}$-DADMAC) or cationic polyacrylamide (CPAM) polymers to $\mathrm{PHL}$ to flocculate the lignin and lignin-derived products. Yasarla and Ramarao (2012) [26] found that this approach resulted in a $40 \%$ loss of sugar took place in spite of achieving $70 \%$ lignin removal. An adsorption concept using lime mud and activated carbon has also been employed to remove inhibitors in PHL. However, these approaches still cause a considerably undesirable sugar adsorption ( 15-20\%). Each of the aforementioned techniques are demonstrated to be unable to simultaneously remove 
solubilized lignin and lignin-derived phenolic substances without hampering recovery of sugars due to their similar molecular weights distribution and water solubility.

Differences in polarity between sugars (hydrophilic) and solubilized lignin (hydrophobic) could be exploited in order to more selectively fractionate inhibitors from target monosaccharides [18]. An approach which manipulates this involves selectively adsorption using porous resins comprised of material whose chemical structures favor interaction with the various inhibitors. Research already exists surrounding lignin-selective adsorptive resins, which have specifically utilized polystyrene divinylbenzene (PS-DVB) resin $[5,27]$. It has been reported that this resin possesses the ability to effectively adsorb soluble lignin and carbohydrate dehydration products in biomass hydrolyzates, owed to the hydrophobic polymeric particles that can selectively adsorb similarly hydrophobic solutes through $\pi-\pi$ ' and van der Waal interactions [27, 28]. Different from the aforementioned separation methods, the adsorbed lignin in the resin can be desorbed and potentially processes for further application. Hence, it is speculated that the PS-DVB resin could be an ideal adsorptive material to simultaneously separate the lignin-derived substances and sugars with great efficiency while still improving the fermentability of PHL.

In present work, acid treatments at different conditions were carried out to hydrolyze PHL xylooligosaccharides into xylose in order to maximize the quantity of available fermentation substrate. Next, a PS-DVB resin adsorption protocol was applied to remove soluble lignin, furfural and HMF. Efficiency and selectivity of this process was verified by compositional analysis upon each stream and as well as nuclear magnetic resonance (NMR) characterization. Furthermore, original PHL and resin-treated $\mathrm{PHL}$ with different concentrations were used to produce the ethanol and XA in order to evaluate the effects of PS-DVB adsorption on the fermentability of PHL. This work will ideally provide a concept to produce value-added chemicals from existing waste streams from pulping process.

\section{Results And Discussion}

\section{Composition analysis of the PHL}

During the pre-hydrolysis stage used for kraft-based dissolving pulp production, the removal extents of hemicellulose and lignin depend upon both treatments conditions and woody feedstock $[5,25]$. In consideration of these variables, it is necessary to obtain a detailed chemical composition for the mixed hardwood PHL used in this work. The chemical compositions of PHL are shown in Table 1. It can be seen that xylose $(86.3 \mathrm{~g} / \mathrm{L})$ and xylooligosaccharide $(32.3 \mathrm{~g} / \mathrm{L})$ are the major sugars in this PHL. In addition, a certain amount of glucose $(7.5 \mathrm{~g} / \mathrm{L})$, arabinose $(6.1 \mathrm{~g} / \mathrm{L})$ and sugar-derived by-products $(0.9 \mathrm{~g} / \mathrm{L}$ of furfural and $0.4 \mathrm{~g} / \mathrm{L}$ of HMF) were also quantified. The high concentration of xylooligosaccharide in PHL confirms that this stream can be further transformed into xylose-rich solution by hydrolyzing xylooligosaccharides into xylose. Comparing to the reported work, it can be seen that the sugars in PHL was significantly higher than those in the PHL (40-60 g/L) used in the work of Shi et al., (2012) [29]. This is due to the used mixed hardwood PHL was obtained after it being concentrated at concentration workshop section by steam. In addition, it is important to note the high concentration $(42.1 \mathrm{~g} / \mathrm{L})$ of 
soluble lignin in PHL. These solutes have the potential to significantly affect efficient biological utilization of PHL [30]. Therefore, it is necessary to remove lignin from PHL that leaves most of the xylose preserved in order to ensure an efficient process for producing ethanol or XA.

To understand the structural information of the chemical compositions in PHL, 2D-HSQC NMR analysis was carried and the obtained spectra are shown in Fig. 1(a). Peak assignments within the HSQC spectra are assigned according to recent works $[5,31,32]$.

The internal xylan units $(X)$ were clear and obvious signals within the spectra. Specifically, the $C_{2} / H_{2}$, $\mathrm{C}_{3} / \mathrm{H}_{3}, \mathrm{C}_{4} / \mathrm{H}_{4}$, and $\mathrm{C}_{5} / \mathrm{H}_{5}$ positions showed the correlation signals at $72.3 / 3.03,73.9 / 3.22,75.3 / 3.48$, and $62.9 / 3.15,3.85 \mathrm{ppm}$, respectively. In addition, xylan with reducing-end units $\left(X_{R}\right)$ were also identified from the $\mathrm{C}_{2} / \mathrm{H}_{2}$ and $\mathrm{C}_{4} / \mathrm{H}_{4}$ correlation signals at $74.4 / 2.89$ and 75.3/3.48 ppm, respectively. The presence of $X_{R}$ indicates that the soluble xylan (xylo-oligosaccharide) in the PHL possess the relatively low degree of polymerization, which makes it a promising resource for xylose production [33].

In addition, the spectra of PHL showed common lignin substructures of $\beta-0-4(A), \beta-\beta(B)$, and $\beta-5(C)$, which can be identified by $\mathrm{C}_{a}-\mathrm{H}_{a}$ signals at $71.8 / 4.86,84.9 / 4.69$, and 86.8/5.49 ppm, respectively.

Correlation signals for syringyl units $(S)$ and guaiacyl units $(G)$ were also noted from their $\mathrm{C}_{2}-\mathrm{H}_{2}$ and $\mathrm{C}_{2,6^{-}}$ $\mathrm{H}_{2,6}$ at $111.0 / 7.01$ and $104.1 / 6.74 \mathrm{ppm}$, respectively. Hence, it can verify the lignin fraction was existed in $\mathrm{PHL}$, which is in accordance to the results in composition analysis.

\section{Acid hydrolysis of the PHL}

In the previous work, it reported that even PS-DVB resin show low affinity for carbohydrate, while a portion of high molecular weight sugars can be still adsorbed by the resin [5,34]. In order to reduce the loss of sugars in PHL after being treated by PS-DVB resin, the oligosaccharide mono-sugars in PHL was intended to be hydrolyzed into mono-saccharide before purification. Acid hydrolysis was carried out with sulfuric acid catalyst at different reaction conditions (acid concentration, time, and temperature) to identify a recipe which maximizes xylooligosaccharide conversion into xylose.

The increase to xylose concentration in the PHL under different acid concentrations (1-5\%) at $100{ }^{\circ} \mathrm{C}$ for $60 \mathrm{~min}$ is shown in Fig. 2a. First, increasing xylose concentrations were found with increasing acid catalyst concentrations. For example, the concentration of xylose in PHL increased from $86.1 \mathrm{~g} / \mathrm{mL}$ to $95.4 \mathrm{~g} / \mathrm{L}$ when acid concentration increased from $1 \%$ to $4 \%$. However, a maximum was noted, as xylose concentration decreased to $88.9 \mathrm{~g} / \mathrm{L}$ when the acid concentration was further increased to $5 \%$. This can be explained by the mechanism that xylose is easily dehydrated into furfural at the higher acid concentration (and temperatures too). As observed by Yang et al., (2012) [35], increasing the acid catalyst (formic acid) concentration from 5-10 g/L could effectively dehydrate xylose into furfural with yields rising from $15.8 \%$ to $74 \%$. Depending on the maximum xylose concentration in PHL, it can be speculated that sulfuric acid with $5 \%$ concentration was the optimum condition to produce the xylose from PHL. 
According to the aforementioned results, the effects of different reaction temperature $\left(90-130{ }^{\circ} \mathrm{C}\right)$ with $4 \%$ acid and 60 min of acid hydrolysis on increases to xylose concentration in PHL were investigated and shown in Fig. 2b. The maximum concentration of xylose in PHL was $95.4 \mathrm{~g} / \mathrm{L}$ at $110^{\circ} \mathrm{C}$. Increasing reaction temperature from $100^{\circ} \mathrm{C}$ to $130^{\circ} \mathrm{C}$ significantly reduced xylose concentrations from $95.4 \mathrm{~g} / \mathrm{L}$ to $75.1 \mathrm{~g} / \mathrm{L}$. This was because increasing reaction temperature further accelerated dehydration of xylose into furfural given the high acid dosage applied in this series of experiments [35]. In the work of Chen et al., (2018) [33], they also found that the xylose in PHL could be further degraded under reaction temperatures from $120^{\circ} \mathrm{C}$ to $135^{\circ} \mathrm{C}$ with $4 \%$ aqueous sulfuric acid for $30 \mathrm{~min}$. Based on the maximum xylose concentration in PHL, it can be speculated that acid hydrolysis with $4 \%$ acid concentration at 100 ${ }^{\circ} \mathrm{C}$ were the optimum conditions to produce the xylose from PHL.

The effect of the reaction time (20-100 min) of acid hydrolysis with $4 \%$ acid at $100{ }^{\circ} \mathrm{C}$ on xylose concentration in PHL is illustrated in Fig. 2c. It can be observed that the xylose concentration in the PHL increased at first and then decreased with increasing reaction time from $20 \mathrm{~min}$ to $100 \mathrm{~min}$. The optimal reaction temperatures was 80 min, where a maximum xylose concentration of $101.1 \mathrm{~g} / \mathrm{L}$ was obtained. Therefore, a highest xylose concentration in PHL with a 17\% increase (relative to original PHL) can be obtained by acid hydrolysis at $100^{\circ} \mathrm{C}$ for 80 min with $4 \%$ sulfuric acid dosage.

Although a higher xylose concentration can be obtained in PHL by applying acid hydrolysis, this method is also shown In this work to unavoidable lead to the dehydration of sugars (xylose and glucose) into fermentation inhibitors (furfural and HMF). As can be seen in Table 1, the acid-treated PHL at the aforementioned ideal condition (A-PHL) contained a higher xylose concentration than the original PHL. However, concentrations of the fermentation inhibitors furfural and HMF were $7.8 \mathrm{~g} / \mathrm{L}$ and $1.9 \mathrm{~g} / \mathrm{L}$. These quantities are significantly higher than those in PHL $(0.9 \mathrm{~g} / \mathrm{L}$ and $0.4 \mathrm{~g} / \mathrm{L})$. In the reported work of Bellido et al (2011) [36], it was found that the pentose-fermenting yeast $P$. stipitis had poor tolerance towards furfural and HMF, with cell growth almost completely inhibited when the fermentation media contained at least $2 \mathrm{~g} / \mathrm{L}$ furfural. In addition, various phenolic compounds formed from the degradation of lignin can also inhibit the efficiency of ethanol fermentation. Zhou et al., (2017) [37] found a significant inhibition effect from furfural occurred using a $G$. oxydans fermentation system with prehydrolyzate containing 6.5 $\mathrm{g} / \mathrm{L}$ furfural, revealing the toxicity of furfural for XA production from $G$. oxydans. In addition, the concentration of water soluble lignin $(44.9 \mathrm{~g} / \mathrm{L})$ was slightly increased in A-PHL relative to PHL. The high concentration ( $>2 \mathrm{~g} / \mathrm{L}$ ) of lignin fractions in the sugar solutions can also cause the inhibitory effect for fermentation. Thus, removing the fermentation inhibitors in A-PHL not only provide a favorable environment for pentose-fermenting yeast but also removes a critical hurdle towards fermentation of xylose to XA by G. oxydans.

\section{Purification of PHL by PS-DVB resin}

Lignin and sugar-derived byproducts in the PHL are difficult to separate from the sugars due to their similar molecular weight and water solubility [27]. In this work, we used a lignin-selective adsorptive resin to separate the lignin and sugars by-products (furfural and HMF) from PHL while retaining most of the 
sugars in the PHL. A diagram for the process used is shown in Fig. 3. As can be seen, the lignin and sugar by-products in PHL can be adsorbed in the resin, while the purified sugars solution proceed to the next unit operation. The ethanol used to regenerate the resin by desorbing the adsorbates can also be recycled to prepare the lignin-based materials. Hence, the present concept for purification of PHL by PS-DVB resin is inherently environmentally friendly and sustainable.

As can be seen in Table 1, concentrations of soluble lignin, HMF, and furfural in PS-DVB treated A-PHL (PA-PHL) were $1.1 \mathrm{~g} / \mathrm{L}, 0.04 \mathrm{~g} / \mathrm{L}$, and $0.61 \mathrm{~g} / \mathrm{L}$. Each of these quantified values are significant lower than those in original A-PHL solution ( $46.9 \mathrm{~g} / \mathrm{L}, 1.9 \mathrm{~g} / \mathrm{L}$, and $7.8 \mathrm{~g} / \mathrm{L}$, respectively). These results indicate that not only $97 \%$ of the lignin can be removed, but also $92-97 \%$ of sugars by-products can also be separated from the xylose solution. In addition, a high proportion (96\%) of xylose was retained in P-A-PHL. These results indicate that the this process can simultaneously separate and recover the lignin and sugars in PHL with yields $>90 \%$, which was more effective than the reported technologies of acidification, nanofiltration or microfiltration, applying cationic polymers (e.g. polydiallyldimethylammonium chloride), activated carbon, or lime mud $[1,19,25]$. Overall, the low concentration of fermentation inhibitors in P-APHL suggest that the fermentability of PHL should be sufficient for producing ethanol and XA. However, it remains to be seen if this removal was sufficient enough to achieve efficient fermentation results.

To further understand the structural changes of the carbohydrate and lignin in A-PHL after being treated by PS-DVB resin, the 2D-HSQC spectra of A-PHL and P-A-PHL were obtained and shown in Fig. $1 \mathrm{~b}$ and Fig. 1c, respectively. It can be seen that A-PHL showed the similar cross-signals for various substructures of lignin and carbohydrate in the 2D-HSQC spectra comparing to those in original PHL spectra (Fig. 1a). However, the signals intensity of $\beta-0-4$ substructures in A-PHL's spectra were significant lower than those in PHL spectra. This might be due to the cleavage of this ether bond under the acidic hydrothermal conditions of acid hydrolysis [29]. For the 2D-HSQC spectra of P-A-PHL, signals observed for carbohydrates remained in similar positions compared to those noted in the A-PHL spectra (Fig. 1C). Importantly, the correlations of lignin substructures and units were absent in P-A-PHL's spectra. This again indicates the successful removal of the lignin from $A-P H L$, which is attribute to the adsorption ability of PS-DVB resin.

\section{Fermentation of A-PHL and P-A-PHL by P. stipitis to produce ethanol}

To understand the fermentability improvement of the A-PHL after being treated by PS-DVB resin, both A$\mathrm{PHL}$ and P-A-PHL (with same initial xylose concentration of $30 \mathrm{~g} / \mathrm{L}$ and $50 \mathrm{~g} / \mathrm{L}$ ) were used as the fermentation stocks to produce ethanol by $P$. stipitis. The concentration of xylose was proposed based on the general tolerance ability of $P$. stipitis for xylose. The fermentation inhibitor concentrations in either sample are listed in Table 2. Xylose consumption and ethanol production of A-PHL and P-A-PHL are shown in Fig. 4a and Fig. 4b, respectively. The ethanol yields, which is defined as the percentage of the total amount of ethanol that could be produced from consumed xylose, are shown in Fig. 4c.

Results in Fig. 4a revealed that A-PHL has low ethanol fermentation productivity by $P$. stipitis. Specifically, xylose in A-PHL was slowly consumed during the fermentation process. After $36 \mathrm{~h}$ of fermentation , 20.2 
$\mathrm{g} / \mathrm{L}$ and $41.6 \mathrm{~g} / \mathrm{L}$ of xylose remained unfermented in the A-PHL with initial xylose concentration of $30 \mathrm{~g} / \mathrm{L}$ and $50 \mathrm{~g} / \mathrm{L}$. These concentrations correlated to a paltry $32.6 \%$ and $16.8 \%$ conversion, respectively. Ethanol yield (Fig. 4c) obtained from the A-PHL with $50 \mathrm{~g} / \mathrm{L}$ xylose was only $12.0 \%$, which was lower than that of A-PHL with $30 \mathrm{~g} / \mathrm{L}$ xylose (23.5\%). The low fermentability of A-PHL for producing the ethanol by $P$. stipitis was therefore due to its high concentration of inhibitors [38,39]. As these samples contain 0.57 $\mathrm{g} / \mathrm{L}$ of HMF and $2.36 \mathrm{~g} / \mathrm{L}$ of furfural in A-PHL with $30 \mathrm{~g} / \mathrm{L}$ xylose and $0.82 \mathrm{~g} / \mathrm{L}$ of HMF and $3.93 \mathrm{~g} / \mathrm{L}$ of furfural in A-PHL with $50 \mathrm{~g} / \mathrm{L}$ xylose. As pointed out by Díaz et al. (2009) [38], an inhibitory effect in ethanol fermentation by $P$. stipitis can be observed with the furfural concentrations of $1-2 \mathrm{~g} / \mathrm{L}$, and almost no sugars can be consumed when there is greater than $4 \mathrm{~g} / \mathrm{L}$ furfural in fermentation media.

From Fig. 4b, it can be seen that PS-DVB resin treatment remarkably improved the fermentability of A-PHL for ethanol production. $80 \%$ and $47 \%$ of xylose in P-A-PHL with initial $30 \mathrm{~g} / \mathrm{L}$ xylose and $50 \mathrm{~g} / \mathrm{L}$ xylose were consumed after $36 \mathrm{~h}$ of fermentation, resulting in ethanol yields of $61.8 \%$ and $45.9 \%$, respectively. Compared to the results of untreated A-PHL with $30 \mathrm{~g} / \mathrm{L}$ and $50 \mathrm{~g} / \mathrm{L}$ xylose, ethanol yields improved by $162 \%$ and $282 \%$, respectively. The improved fermentability of P-A-PHL therefore must be due to the removal of carbohydrate-degradation products (HMF and furfural) and lignin-degradation products. As can be seen in Table 3, the concentration of HMF, furfural, and lignin-degradation products in P-A-PHL with $30 \mathrm{~g} / \mathrm{L}$ and $50 \mathrm{~g} / \mathrm{L}$ xylose were $0 \mathrm{~g} / \mathrm{L}, 0.21-0.30 \mathrm{~g} / \mathrm{L}$, and 0.75-1.01 g/L, significant lower than those in untreated A-PHL. In view the other technologies have been done to improve the fermentability of sugar solution with inhibitors, Lai et al., (2016) [39] reported that the ethanol production increased by $45.5 \%$ and $42.8 \%$ could be achieved for the prehydrolyzate treated by cetyltrimethylammonium- and benzyltrimethylammonium-modified bentonites, respectively. Zhu et al., (2011) [40] reported that a trialkylamine extraction technology to remove $45.7 \%$ of HMF and $100 \%$ of furfural could be removed from prehydrolyzate, which could improve its fermentability by P. stipitis with a degree of $89.6 \%$. Based on the aforementioned results, it can be concluded that PS-DVB resin treatment was a valid detoxification method to improve PHL fermentability for ethanol production.

\section{Fermentation of A-PHL and P-A-PHL for producing XA by G. oxydans}

The fermentability of A-PHL treated by PS-DVB resin with different xylose concentration (40,90, and 150 $\mathrm{g} / \mathrm{L}$ ) were investigated and shown in Fig. 5. Fig.5a shows that the xylose in A-PHL with $40 \mathrm{~g} / \mathrm{L}$ xylose could be completely consumed within $48 \mathrm{~h}$, resulting in a XA production of $44.4 \mathrm{~g} / \mathrm{L}$ and a corresponding yield of $96.6 \%$ (Fig.5c). When increasing the A-PHL's xylose concentration to $90 \mathrm{~g} / \mathrm{L}$, even a better XA production with $58.8 \mathrm{~g} / \mathrm{L}$ could be achieved at $48 \mathrm{~h}$. However, at the aforementioned conditions, only $49.7 \%$ of the xylose was consumed by $G$. oxydans to produce XA with a yield of $60.6 \%$. When further increasing the A-PHL's xylose concentration to $150 \mathrm{~g} / \mathrm{L}$, only $12.1 \%$ of the xylose could be consumed to produce the XA with a yield of $12.1 \%(4.7 \mathrm{~g} / \mathrm{L})$ at $48 \mathrm{~h}$. The bioconversion of xylose in A-PHL was strongly inhibited by the increased concentration xylose was due to the corresponding increased concentration of furfural in A-PHL. As can be seen in Table S1, A-PHL with $40 \mathrm{~g} / \mathrm{L}$ and $90 \mathrm{~g} / \mathrm{L}$ xylose contained $3.16 \mathrm{~g} / \mathrm{L}$ and $6.96 \mathrm{~g} / \mathrm{L}$ of furfural, which were within the tolerance of $\mathrm{G}$. oxydans to produce XA. Meanwhile, there was $10.8 \mathrm{~g} / \mathrm{L}$ of furfural in the A-PHL with $40150 \mathrm{~g} / \mathrm{L}$ xylose, which is beyond the 
tolerance threshold for bioconversion. As pointed out by Zhou et al., (2018) [37], the bioconversion ability of $G$. oxydans can be reduced by $60 \%$ when the furfural concentration was increases from $~ 10$ to $15 \mathrm{~g} / \mathrm{L}$.

Since high concentrations of furfural causes severe inhibition of bioconversion ability of G. oxydans [41], we also tried to use the PS-DVB resin treated A-PHL (P-A-PHL) to produce the XA by G. oxydans. As can be seen in Fig.5b, a predictably enhanced productivity of XA with $71.6 \%$ and $26.1 \%$ yields were achieved from P-A-PHL with $90 \mathrm{~g} / \mathrm{L}$ and $150 \mathrm{~g} / \mathrm{L}$ xylose, which were improved by $18 \%$ and $828 \%$ comparing to those of A-PHL with $90 \mathrm{~g} / \mathrm{L}$ and $150 \mathrm{~g} / \mathrm{L}$ xylose, respectively. The tremendous improvement of the A-PHL was due to its low concentration of furfural (as shown in Table S1), which was achieved by PS-DVB treatment. According to the research of Chai et al.(2013) [42], the inhibition by furfural toward whole-cell catalysis of $G$. oxydans can be avoided by implementation of furfural removal. Our observations support this previous finding. In all, it can be concluded that PS-DVB resin treatment was also a potential detoxification method for PHL to improve its fermentability for XA production, especially from the PHL with high concentrations of xylose.

\section{Conclusion}

Acid-hydrolysis was used to treat PHL to enrich its xylose concentration. However, concentration of furanic fermentation inhibitors were inevitably increased in A-PHL despite successful generation of fermentable xyloses. Using PS-DVB resin was found to be an effective adsorptive medium capable of simultaneously removing fermentation inhibitors while retaining monosaccharides. After PS-DVB treatment, the ethanol production yield of sequentially treated liquor with $30 \mathrm{~g} / \mathrm{L}$ and $50 \mathrm{~g} / \mathrm{L}$ xylose improved by $162 \%$ and $282 \%$, respectively. A similarly elevated productivity of $18 \%$ and $828 \%$ could be achieved for XA production from same treated liquor with $90 \mathrm{~g} / \mathrm{L}$ and $150 \mathrm{~g} / \mathrm{L}$ xylose, respectively.

\section{Methods}

\section{Materials}

PHL from mixed hardwood, was kindly provided by Sun Paper Co., Ltd (Shandong province, China). All chemical reagents were purchased from the supplier without purification. Pichia stipites (P. stipitis) yeast and Gluconobacter oxydans (G. oxydans) were provided by Biochemical Engineering Research Institute of Nanjing Forestry University.

\section{Acid hydrolysis of PHL}

Acid hydrolysis was carried out at different conditions to hydrolyze the xylooligosaccharide into xylose. Specifically, a certain amount of concentrated sulfuric acid $(98 \%, w / v)$ was added to PHL to final acid concentrations of $1-6 \%(\mathrm{w} / \mathrm{v})$. Acid hydrolysis was carried out in $100 \mathrm{~mL}$ autoclave bombs at $90-130{ }^{\circ} \mathrm{C}$ for 20-100 min. After acid hydrolysis, an aliquot was withdrawn for xylose analysis. 
The hydrophobic PS-DVB resin was used to remove lignin-derived substances, furfural, and HMF from PHL. Specifically, resin particles were sealed inside of a Chromafex glass column $(40 \times 2 \mathrm{~cm})$ and then sequentially washed with water, ethanol, and water to remove the preservative salts, adsorbed impurity, and ethanol, respectively. Next, $500 \mathrm{~mL}$ of the acid-hydrolyzed PHL (A-PHL) was passed through the resin column by the pump at $2 \mathrm{~mL} / \mathrm{min}$. All the conditions were carried out according to the work in Narron et al [27]. The permeated solution (purified PHL) was collected and termed P-A-PHL. After elution of P-A-PHL, $50 \mathrm{~mL}$ of deionized water was passed through to obtain any soluble sugars that remained unadsorbed within the column. Next, 1.5 L of anhydrous ethanol was eluted through the column to desorb the adsorbates. A final water wash was applied to remove ethanol prior to recovery and re-use of the resin.

\section{Fermentation of PHL into ethanol}

$P$. stipitis was used to ferment xylose into ethanol. To activate and inoculate the $P$. stipitis, the yeast was loaded in the seed culture solution containing $20 \mathrm{~g} / \mathrm{L}$ xylose, $3 \mathrm{~g} / \mathrm{L}$ peptone, and $5 \mathrm{~g} / \mathrm{L}$ yeast extraction and cultured for $72 \mathrm{~h}$ at $30^{\circ} \mathrm{C}$ under shaking at $150 \mathrm{rpm}$. Once the optimal optical density of yeast reached 15 , the yeast cells were harvested by centrifugation and then inoculated into the fermentation media ( $\mathrm{pH}$ 6). This media contained $0.08 \mathrm{~g} / \mathrm{L} \mathrm{MgSO}_{4}, 2.5 \mathrm{~g} / \mathrm{L} \mathrm{KH}_{2} \mathrm{PO}_{4}, 0.25 \mathrm{~g} / \mathrm{L} \mathrm{CaCl}_{2}, 0.24 \mathrm{~g} / \mathrm{L}$ urea and the P-A-PHL solutions ( $30 \mathrm{~g} / \mathrm{L}$ and $50 \mathrm{~g} / \mathrm{L}$ ). Xylose fermentation was carried out at at $30^{\circ} \mathrm{C}$ with $150 \mathrm{rpm}$ shaking for $36 \mathrm{~h}$. To evaluate the fermentability difference of PHL after purification, A-PHL with the same concentrations were also fermented at the same conditions. During fermentation, an aliquot was withdrawn for xylose and ethanol analysis at regular intervals. Ethanol yield was calculated according to the following equation:

Ethanol yield $(\%)=\frac{\text { Produced ethanol }(\mathrm{g})}{\text { Consumed } x y l o s e \times 0.46(\mathrm{~g})} \times 100 \%$

\section{Whole-cell catalysis of PHL into xylonic acid}

G. oxydans NL71 was used to ferment xylose into XA by whole-cell catalysis. To activate and inoculate $G$. oxydans, the bacterium was loaded into a seed culture solution containing $80 \mathrm{~g} / \mathrm{L}$ of sorbitol and $8 \mathrm{~g} / \mathrm{L}$ of yeast extract and cultured at $30^{\circ} \mathrm{C}$ and shaken at $220 \mathrm{rpm}$ for $24 \mathrm{~h}$. Once cell density reached $4 \mathrm{~g} / \mathrm{L}$, cells were harvested by centrifugation and then inoculated into the fermentation media $(\mathrm{pH} \mathrm{5.8)}$. This

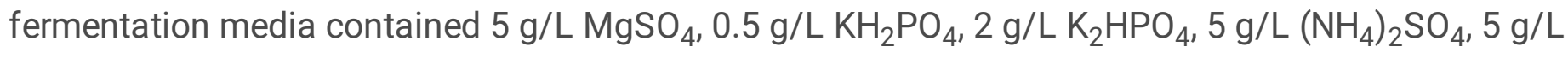
yeast extract and the P-A-PHL solutions $(40 \mathrm{~g} / \mathrm{L}, 90 \mathrm{~g} / \mathrm{L}$ and $150 \mathrm{~g} / \mathrm{L})$. Whole-cell catalysis of PHL was carried out at $30^{\circ} \mathrm{C}$ with $220 \mathrm{rpm}$ shaking for $48 \mathrm{~h}$. To evaluate the fermentability difference of PHL after purification, A-PHL with the same concentrations were also fermented at the same conditions. During fermentation, an aliquot was withdrawn for xylose and XA analysis at regular intervals. XA yield was calculated according to the following equation:

$\mathrm{XA}$ yield $(\%)=\frac{\text { Produced } \mathrm{XA}(\mathrm{g})}{\text { Consumed } \mathrm{xylose} \times 1.1(\mathrm{~g})} \times 100 \%$ 


\section{Analytical methods}

Monosaccharide (glucose and xylose), ethanol, and fermentation inhibitors (furfural and HMF) concentrations were detected by high performance liquid chromatography (HPLC) system consisted of Aminex $\mathrm{HPX}-87 \mathrm{H}$ column with $50 \mathrm{mM} \mathrm{H}_{2} \mathrm{SO}_{4}$ as eluent at a flow rate of $0.6 \mathrm{~mL} / \mathrm{min}$ [43].

The concentration of oligosaccharides in PHL were determined by back calculation using xylose concentrations before and after acid hydrolysis. Specifically, an aliquot of hydrolyzate was mixed with sulfuric acid to reach $4 \%$ acid concentration and hydrolyzed at $121^{\circ} \mathrm{C}$ for $60 \mathrm{~min}$. The concentration of oligo-saccharides was calculated by the differences of respective monosaccharides contents before and after acid hydrolysis, which were also detected using the above HPLC system.

Concentrations of XA were determined by a high performance anion-exchange chromatography (HPAEC) system using a CarboPacTM PA10 column and $\mathrm{NaOH}$ and sodium acetate as eluents at a flow rate of 0.3 $\mathrm{mL} / \mathrm{min}$. The separation method to analyze XA concentrations in HPAEC was according to the work of Zhou and Xu (2019) [44].

The concentrations of soluble lignin in P-A-PHL and PHL were determined by using the Lambert-Beer law $(A=\bigotimes b c)$, in which the absorbance was obtained from UV spectrophotometry at $280 \mathrm{~nm}$.

Chemical structures of PHL, A-PHL, and P-A-PHL were recorded by two-dimensional heteronuclear singlequantum coherence (2D-HSQC) on a Bruker AVIII $600 \mathrm{MHz}$ spectrometer. $50 \mathrm{mg}$ of material was dissolved in $0.5 \mathrm{~mL} \mathrm{DMSO}-\mathrm{d}_{6}$ to obtain 2D-HSQC spectra according to our previous work [45].

\section{Abbreviations}

PHL: pre-hydrolysis liquor; PS-DVB:polystyrene divinylbenzene; A-PHL:acid-hydrolysis; XA:xylosic acid; HMF:hydroxymethylfurfural; p-DADMAC:polydiallyldimethylammonium chloride; NMR:nuclear magnetic resonance; HPLC:high performance liquid chromatography; HPAEC:high performance anion-exchange chromatography

\section{Declarations}

\section{Ethics approval and consent to participate}

Not applicable.

\section{Consent for publication}

Not applicable.

\section{Availability of data and material}


All data generated and analyzed in this study are included in this published article.

\section{Competing interests}

The authors declare that they have no competing interests.

\section{Funding}

This work was supported by the National Natural Science Foundation of China (31800501) and Natural Science Foundation of Jiangsu Province (BK20180772).

\section{Authors' contributions}

$\mathrm{CH}$ developed the idea for the study, performed the research, data analysis and prepared the manuscript. WL and YS performed the research and data analysis. YZ helped to prepare the PS-DVB resin. QY revised the manuscript. All authors read and approved the final manuscript.

\section{Acknowledgements}

The authors thank Pro. Yong Xu and Dr. Xin Zhou in Nanjing Forestry University for providing the technologies to do XA fermentation assays.

\section{References}

1. Domínguez-Robles J, del Valle Palenzuela M, Sánchez R, Loaiza, JM, Espinosa, E, Rosal A., Rodríguez A. Coagulation-flocculation as an alternative way to reduce the toxicity of the black liquor from the paper industry. thermal valorization of the solid biomass recovered. Waste Biomass Valori. 2019;112.

2. Wang Z, Jiang J, Wang X, Fu Y, Li Z, Zhang F, Qin M. Selective removal of phenolic lignin derivatives enables sugars recovery from wood prehydrolysis liquor with remarkable yield. Bioresour. Technol. 2014; 174: 198-203.

3. Shi H, Fatehi P, Xiao H, Ni Y. Optimizing the poly ethylene oxide flocculation process for isolating lignin of prehydrolysis liquor of a kraft-based dissolving pulp production process. Ind. Eng. Chem. Res. 2012;51(14):5330-5335.

4. Yang G, Jahan M S, Liu H, Ni Y. Acid hydrolysis of prehydrolysis liquor produced from the kraft-based dissolving pulp production process. Ind. Eng. Chem. Res. 2012;51(43):13902-13907.

5. Huang C, Lin W, Lai C, Li X, Jin Y, Yong Q. Coupling the post-extraction process to remove residual lignin and alter the recalcitrant structures for improving the enzymatic digestibility of acid-pretreated bamboo residues. Bioresour. Technol. 2019;285:121355. 
6. Adams TN. Kraft recovery boilers. TAPPI press 1997.

7. Farhat $W$, Venditti RA, Hubbe $M$, Taha M, Becquart F, Ayoub A. A review of water-resistant hemicellulose-based materials: processing and applications. ChemSusChem 2017;10(2):305-323.

8. Moncada J, Aristizábal V. Design strategies for sustainable biorefineries. Biochem Eng J. 2016;116:122-34.

9. Nizami AS, Rehan M, Waqas M, Naqvi M, Ouda OKM, Shahzad K, Pant D. Waste biorefineries: enabling circular economies in developing countries. Bioresour Technol. 2017;241:1101-17.

10. Pei W, Shang W, Liang C, Jiang X, Huang C, Yong Q. Using lignin as the precursor to synthesize Fe304@ lignin composite for preparing electromagnetic wave absorbing lignin-phenol-formaldehyde adhesive. Ind Crop Prod. 2020;154:112638.

11. Sainio T, Kallioinen M, Nakari $O$, Mänttäri M. Production and recovery of monosaccharides from lignocellulose hot water extracts in a pulp mill biorefinery. Bioresour Technol. 2013;135:730-7.

12. Gupta KK, Rehman A, Sarviya RM. Bio-fuels for the gas turbine: A review. Renew Sust Energ Rev. 2010;14(9):2946-55.

13. Zhou X, Xu Y. Eco-friendly consolidated process for co-production of xylooligosaccharides and fermentable sugars using self-providing xylonic acid as key pretreatment catalyst. Biotechnol Biofuels. 2019;12(1):1-10.

14. Zhang H, Liu G, Zhang J, Bao J. Fermentative production of high titer gluconic and xylonic acids from corn stover feedstock by Gluconobacter oxydans and techno-economic analysis. Bioresour Technol. 2016;219:123-31.

15. Lavarack BP, Griffin GJ, Rodman D. The acid hydrolysis of sugarcane bagasse hemicellulose to produce xylose, arabinose, glucose and other products. Biomass Bioenerg. 2002;23(5):367-80.

16. Cao L, Chen H, Tsang DC, Luo G, Hao S, Zhang S, Chen J. Optimizing xylose production from pinewood sawdust through dilute-phosphoric-acid hydrolysis by response surface methodology. $\mathrm{J}$ Clean Prod. 2018;178:572-9.

17. Modenbach AA, Nokes SE. The use of high-solids loadings in biomass pretreatment-a review. Biotechnol Bioeng. 2012;109(6):1430-42.

18. Jiang $X$, Narron RH, Han Q, Park S, Chang HM, Jameel H. Tracing Sweetgum Lignin's Molecular Properties through Biorefinery Processing. ChemSusChem. 2020; doi: 10.1002/cssc.202001125.

19. Fatehi P, Shen J, Hamdan FC, Ni Y. Improving the adsorption of lignocelluloses of prehydrolysis liquor on precipitated calcium carbonate. Carbohyd Polym. 2013;92(2):2103-10.

20. He J, Huang C, Lai C, Huang C, Li X, Yong Q. Elucidation of structure-inhibition relationship of monosaccharides derived pseudo-lignin in enzymatic hydrolysis. Ind Crop Prod. 2018;113:368-75.

21. Goundalkar MJ, Bujanovic B, Amidon TE. Analysis of non-carbohydrate based low-molecular weight organic compounds dissolved during hot-water extraction of sugar maple. Cell Chem Technol. 2010;44(1):27. 
22. Sun RC. Detoxification and separation of lignocellulosic biomass prior to fermentation for bioethanol production by removal of lignin and hemicelluloses. BioResources. 2009;4(2):452-5.

23. Hahn-Hägerdal B, Karhumaa K, Fonseca C, Spencer-Martins I, Gorwa-Grauslund MF. Towards industrial pentose-fermenting yeast strains. App Microbiol Biot. 2007;74(5):937-53.

24. Shi H, Fatehi P, Xiao H. A combined acidification/PEO flocculation process to improve the lignin removal from the pre-hydrolysis liquor of kraft-based dissolving pulp production process. Bioresour Technol. 2011;102(8):5177-82., Ni Y ..

25. Wang Z, Wang X, Jiang J, Fu Y, Qin M. Fractionation and characterization of saccharides and lignin components in wood prehydrolysis liquor from dissolving pulp production. Carbohyd Polym. 2015;126:185-91.

26. Yasarla LR, Ramarao BV. Dynamics of flocculation of lignocellulosic hydrolyzates by polymers. Ind. 2012;51(19):6847-61. E C Res ..

27. Narron RH, Chang HM, Jameel H, Park S. Soluble lignin recovered from biorefinery pretreatment hydrolyzate characterized by lignin-carbohydrate complexes. ACS Sustain Chem Eng. 2017;5(11):10763-71.

28. Huck CW, Bonn GK. Poly (Styrene-Divinylbenzene) Based Media for Liquid Chromatography. Chem Eng Technol. 2005;28(12):1457-72.

29. Chen X, Cao X, Sun S, Yuan T, Wang S, Shi Q, Sun R. Hydrothermal acid hydrolysis for highly efficient separation of lignin and xylose from pre-hydrolysis liquor of kraft pulping process. Sep Purif Technol. 2019;209:741-7.

30. Bajwa PK, Pinel D, Martin VJ, Trevors JT, Lee H. Strain improvement of the pentose-fermenting yeast Pichia stipitis by genome shuffling. J Microbiol Meth. 2010;81(2):179-86.

31. Shen XJ, Chen T, Wang HM, Mei Q, Yue F, Sun S, Wen JL, Yuan TQ, Sun RC. Structural and morphological transformations of lignin macromolecules during bio-based deep eutectic solvent (DES) pretreatment. ACS Sustain Chem Eng. 2019;8(5):2130-7.

32. Wang HM, Ma CY, Li HY, Chen TY, Wen JL, Cao XF, Wang XL, Yuan TQ, Sun RC. Structural variations of lignin macromolecules from early growth stages of poplar cell walls. ACS Sustain Chem Eng. 2019;8(4):1813-22.

33. Chen X, Cao X, Sun S, Yuan T, Shi Q, Zheng L, Sun R. Evaluating the production of monosaccharides and xylooligosaccharides from the pre-hydrolysis liquor of kraft pulping process by acid and enzymatic hydrolysis. Ind Crop Prod. 2018;124:906-11.

34. Lin SH, Juang RS. Adsorption of phenol and its derivatives from water using synthetic resins and low-cost natural adsorbents: a review. J Environ Manage. 2009;90(3):1336-49.

35. Yang W, Li P, Bo D, Chang $\mathrm{H}$. The optimization of formic acid hydrolysis of xylose in furfural production. Carbohyd Res. 2012;357:53-61.

36. Bellido C, Bolado S, Coca M, Lucas S, González-Benito G, García-Cubero MT. Effect of inhibitors formed during wheat straw pretreatment on ethanol fermentation by Pichia stipitis. Bioresour Technol. 2011;102(23):10868-74. 
37. Zhou X, Zhou X, Xu Y, Chen RR. Gluconobacter oxydans (ATCC 621H) catalyzed oxidation of furfural for detoxification of furfural and bioproduction of furoic acid. $J$ Chem Technol Biot. 2017;92(6):1285-9.

38. Díaz MJ, Ruiz E, Romero I, Cara C, Moya M, Castro E. Inhibition of Pichia stipitis fermentation of hydrolysates from olive tree cuttings. World J Microb Biot. 2009;25(5):891-9.

39. Lai C, Li X, Zhu J, Yu S, Yong Q. Detoxification of steam-exploded corn stover prehydrolyzate with organobentonite enhances ethanol fermentation by Pichia stipitis. Bioresources. 2016;11(1):190518.

40. Zhu J, Yong Q, Xu Y, Yu S. Detoxification of corn stover prehydrolyzate by trialkylamine extraction to improve the ethanol production with Pichia stipitis CBS 5776. Bioresour Technol. 2011;102(2):16638.

41. Zhao J, Zhang X, Lei W, Ji X, Zhou X, Xu Y. Mannonic acid and bio-ethanol production from konjac using a two-step bioprocess with Candida shehatae and Gluconobacter oxydans. J Renew Mater. 2020;8(1):79.

42. Chai WM, Liu X, Hu YH, Feng HL, Jia YL, Guo YJ, Zhou HT, Chen QX. Antityrosinase and antimicrobial activities of furfuryl alcohol, furfural and furoic acid. Int J Biol Macromol. 2013;57:151-5.

43. Lin W, Xing S, Jin Y, Lu X, Huang C. Yong Q Insight into understanding the performance of deep eutectic solvent pretreatment on improving enzymatic digestibility of bamboo residues. Bioresour. Technol. 2020;123163.

44. Zhou X, Xu Y. Integrative process for sugarcane bagasse biorefinery to co-produce xylooligosaccharides and gluconic acid. Bioresour Technol. 2019;282:81-7.

45. Dong H, Zheng L, Yu P, Jiang Q, Wu Y, Huang C, Yin B. Characterization and application of lignincarbohydrate complexes from lignocellulosic materials as antioxidants for scavenging in vitro and in vivo reactive oxygen species. ACS Sustain Chem Eng. 2019;8(1):256-66.

\section{Tables}

Table 1: Composition analysis of the PHL, A-PHL, and P-A-PHL (g/L) 


\begin{tabular}{|llll|}
\hline & $\mathrm{PHL}^{\mathrm{a}}$ & $\mathrm{A}^{-} \mathrm{PHL}{ }^{\mathrm{b}}$ & $\mathrm{P}^{-}-\mathrm{PHL}^{\mathrm{c}}$ \\
\hline Xylose & 86.3 & 101.1 & 97.1 \\
\hline Glucose & 7.52 & 8.8 & 8.4 \\
\hline Arabinose & 6.1 & 4.5 & 4.3 \\
\hline HMF & 0.4 & 1.9 & 0.04 \\
\hline Furfural & 0.9 & 7.8 & 0.61 \\
\hline Xylo-oligosaccharide & 32.3 & $/$ & $/$ \\
\hline Gluco-oligosaccharides & 3.3 & $/$ & $/$ \\
\hline Soluble lignin & 42.1 & 42.9 & 2.1 \\
\hline
\end{tabular}

a: pre-hydrolysis liquor

b: PHL after being acid-hydrolysis

c: A-PHL after purification by by PS-DVB resin

Table 2: Composition analysis of A-PHL and P-A-PHL with different xylose concentration $(\mathrm{g} / \mathrm{L})$

\begin{tabular}{|lllllllllll|}
\hline & A-PHL & \multicolumn{1}{c|}{ P-A-PHL } \\
Xylose & 30 & 40 & 50 & 90 & 150 & 30 & 40 & 50 & 90 & 150 \\
HMF & 0.57 & 0.75 & 0.82 & 1.79 & 2.80 & 0 & 0 & 0 & 0.05 & 0.1 \\
\hline Furfural & 2.36 & 3.16 & 3.93 & 6.96 & 10.8 & 0.21 & 0.25 & 0.30 & 0.59 & 1.22 \\
Soluble lignin & 15.41 & 20.12 & 23.52 & 41.25 & 59.89 & 0.75 & 0.86 & 1.01 & 2.15 & 3.04 \\
\hline
\end{tabular}

\section{Figures}



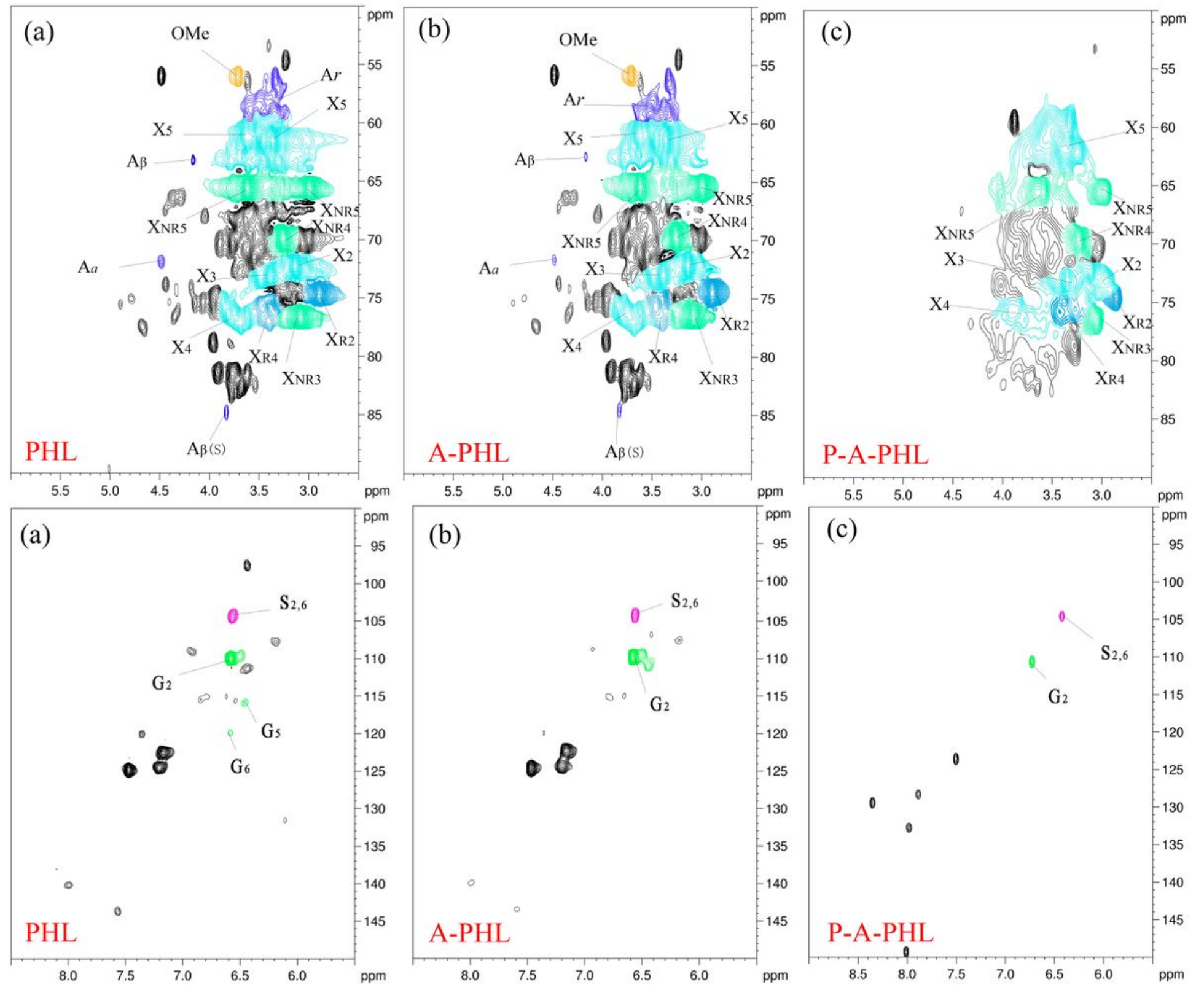

\section{Figure 1}

2D-HSQC NMR spectra of PHL (a), A-PHL (b), P-A-PHL (c) 

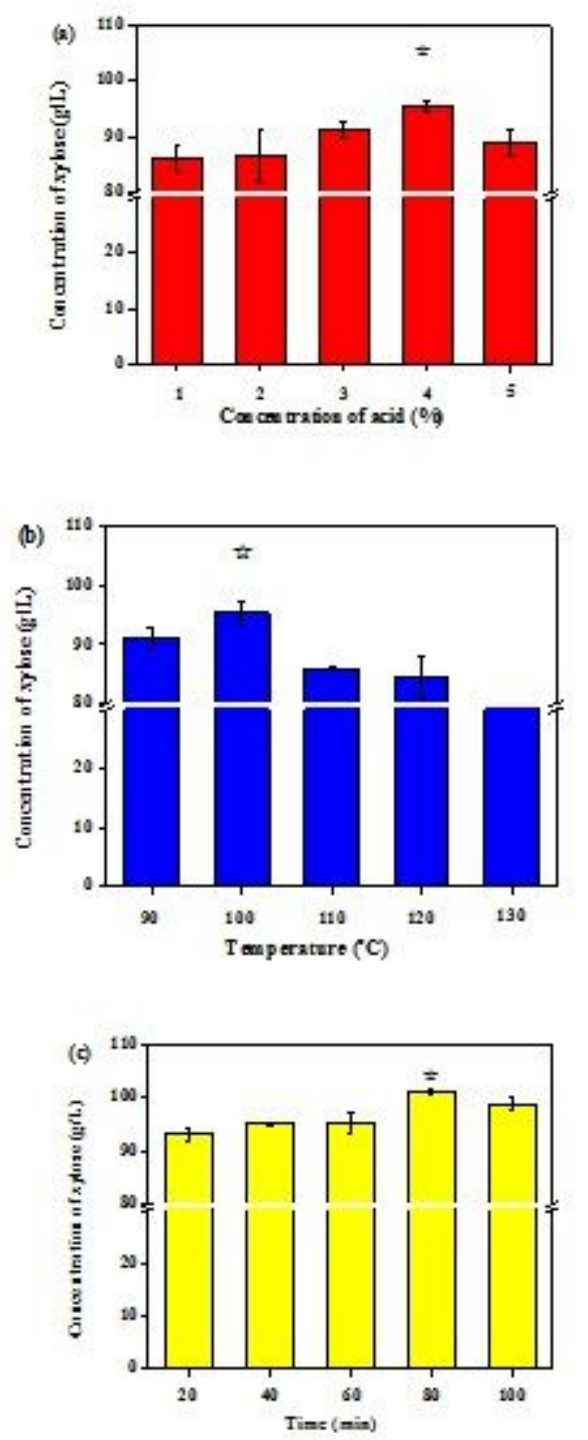

Figure 2

Effect of different reaction conditions of acid-hydrolysis on xylose production (acid concentration (a), temperature (b), and time (c)) 


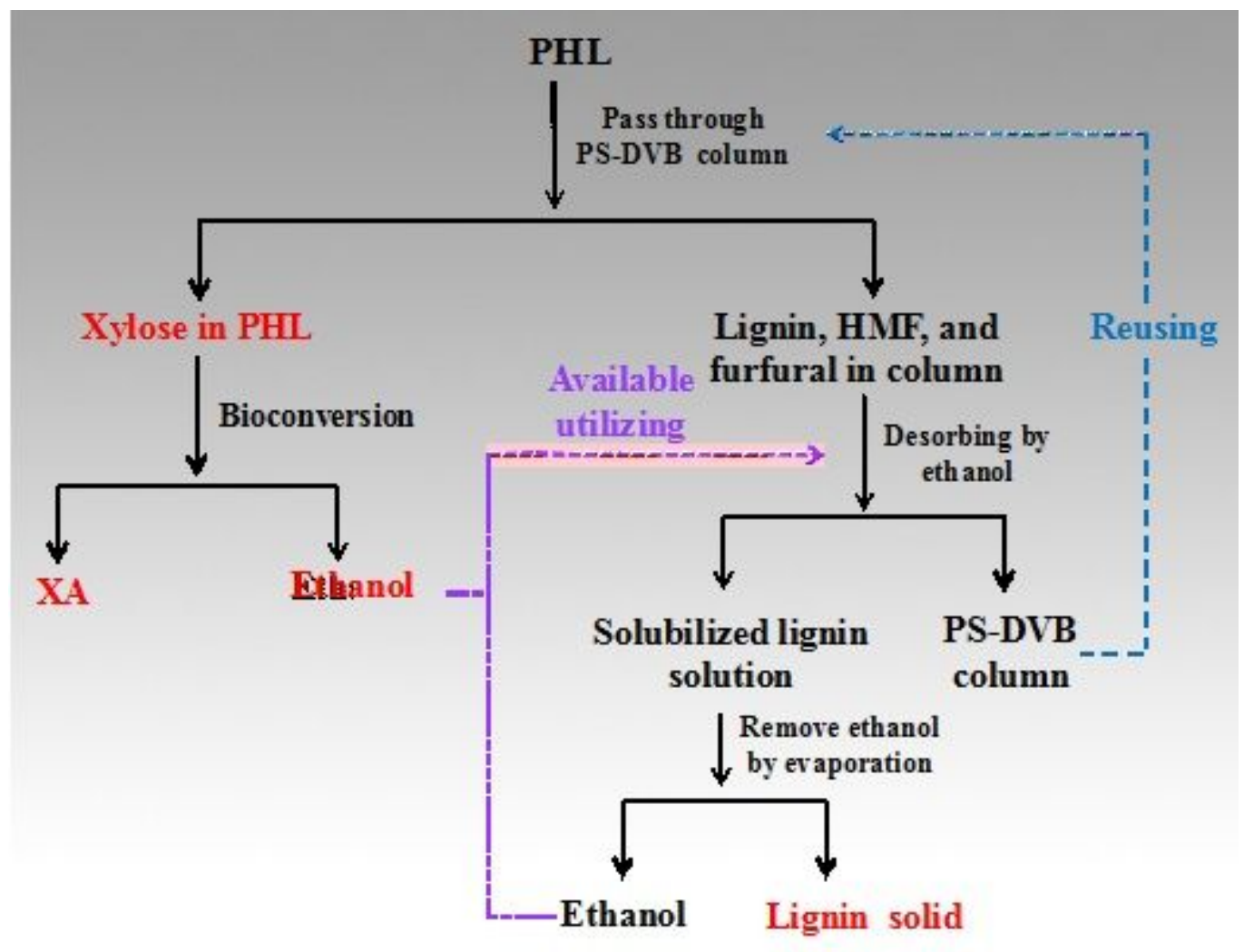

Figure 3

The proposed process diagram to remove lignin and sugars by-products (furfural and HMF) from PHL 

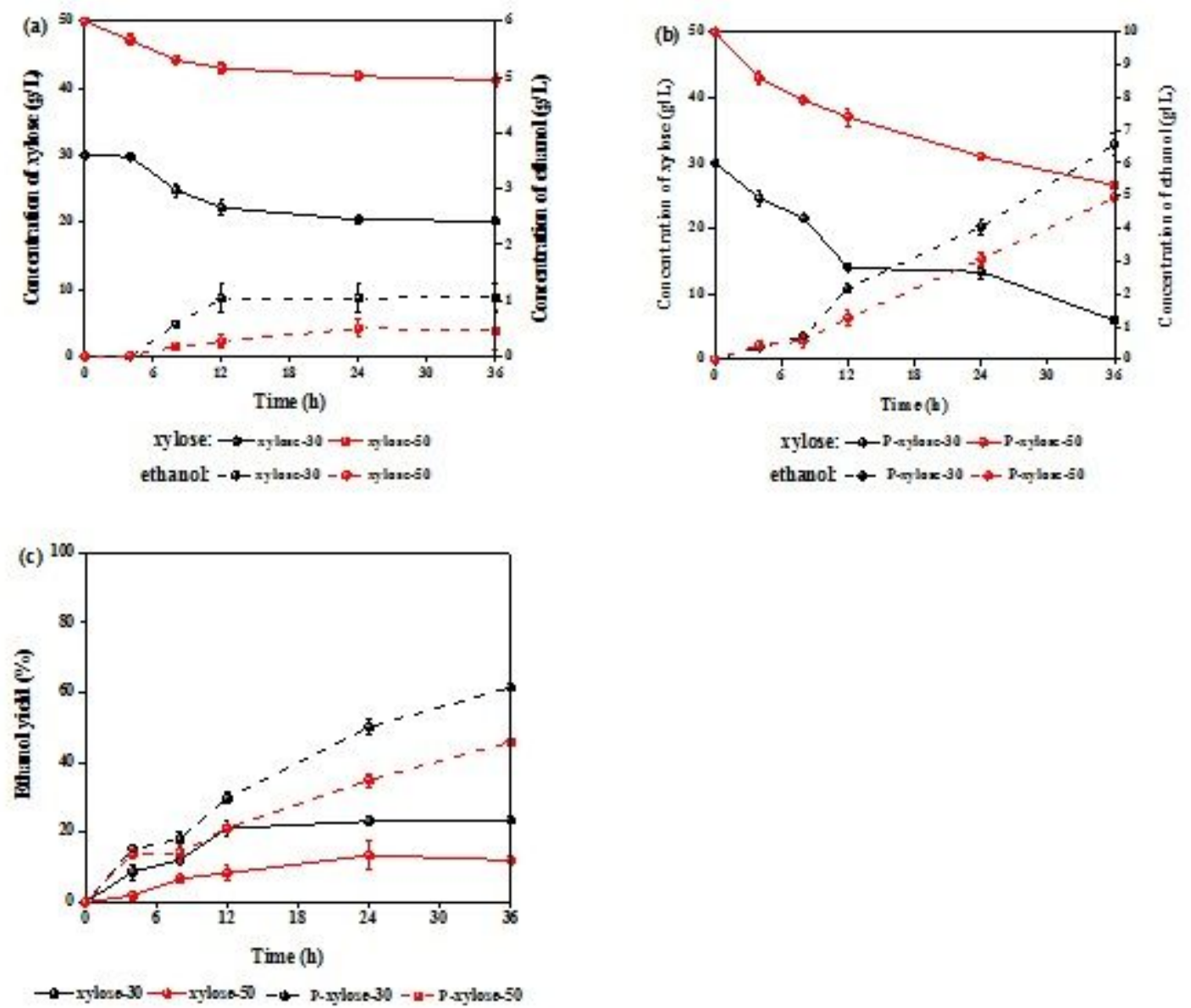

Figure 4

The xylose consumption and ethanol production of A-PHL (a) and P-A-PHL (b), and their ethanol yields (c) 


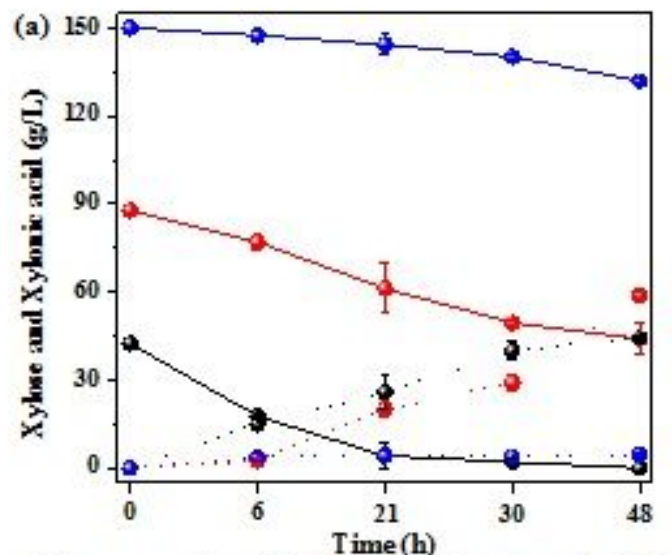

Xylose: $\rightarrow-x y$ lose-40 $\rightarrow-x y l o s e-90 \rightarrow x y l o s e-150$

XA: $* x y l o s e-40 \cdot x y l o s e-90 \cdots \cdot x y l o s e-150$

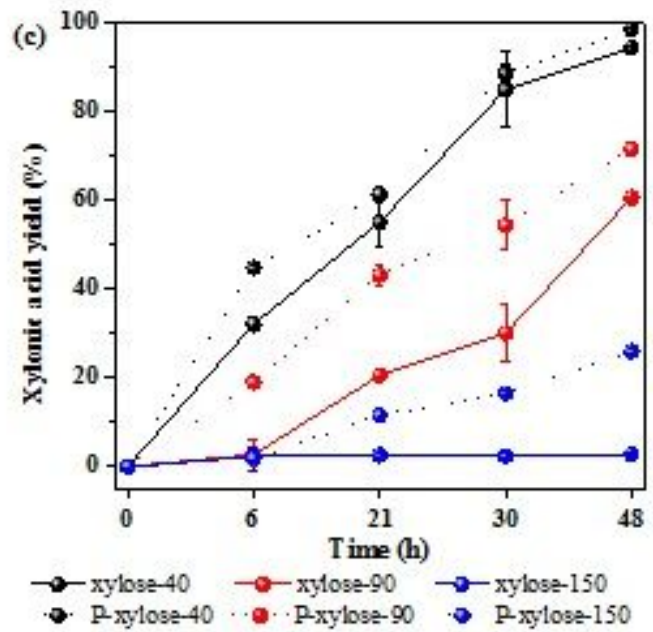

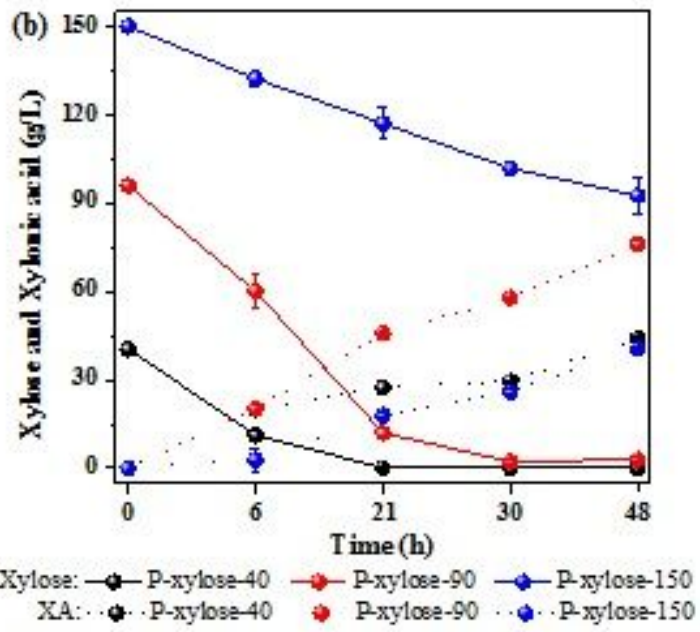

\section{Figure 5}

Xylose consumption and XA production of A-PHL (a) and P-A-PHL (b), and their XA yields (c) 